\title{
Peertechz
}

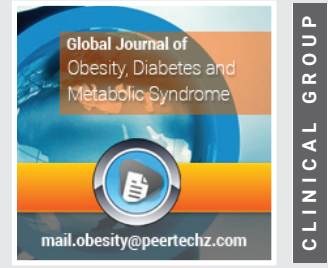

\section{Relationship between death anxiety and health-related quality of life among diabetic patients: The predictive roles of experiential avoidance}

\author{
Emmanuel Sochukwuma Ezaka', Reyam Nehad Nassif², Okoli Paul \\ Chibuike $^{3 *}$, Suhanya Okeke ${ }^{3,4}$, Okpara Titus Chukwubuzo ${ }^{3}$, Chime Peter \\ Ekpunobi $^{3}$, Ozougwu Augustine Obumneme ${ }^{3}$ and Okoli Alexander \\ Chinwike ${ }^{5}$ \\ 'Department of psychology, University of Nigeria, Nsukka, Enugu, Nigeria \\ ${ }^{2}$ Department of Psychiatry and Behavioral Neurosciences, McMaster University, Ontario, Canada \\ ${ }^{3}$ Department of Internal Medicine, College of Medicine, Enugu State University of Science and \\ Technology, Enugu, Nigeria \\ ${ }^{4}$ Department of Ophthalmology, College of Medicine, Enugu State University of Science and \\ Technology, Enugu, Nigeria \\ ${ }^{5}$ Department of Psychology, Nnamdi Azikiwe University, Awka, Anambra State, Nigeria
}

Received: 19 January, 2022

Accepted: 25 January, 2022

Published: 27 January, 2022

*Corresponding author: Okoli Paul Chibuike, Department of Internal Medicine, College of Medicine, Enugu State University of Science and Technology, Enugu, Nigeria, Tel: +2348037110292; E-mail: okolipd71@gmail.com

Keywords: Experiential avoidance; Death anxiety; Diabetes; Diabetes mellitus; Quality of life

Copyright License: (c) 2022 Ezaka ES, et al. This is an open-access article distributed under the terms of the Creative Commons Attribution License, which permits unrestricted use, distribution, and reproduction in any medium, provided the original author and source are credited.

https://www.peertechzpublications.com

Check for updates

\section{Abstract}

This study investigated the predictive roles of experiential avoidance on the relationship between death anxiety and health-related quality of life among diabetic patients. A total of one hundred and five (105) participants (62; 58.5\% females) participated in the study. The participant ages ranged from $21-75$ years with a mean age of 53.45 and a standard deviation of 14.44. Participants were drawn using the convenience sampling technique and were administered the questionnaires before their consultations. Three instruments were used in data collation namely; the Death Anxiety Inventory-Revised (DAI-R), the Acceptance and Action Questionnaire (AAQ), and the Diabetes Quality of Life Questionnaire (DQOLQ). Four hypotheses were tested and the results showed that there was no significant correlation between death anxiety and HRQoL ( $r=-.036)$, also, experiential avoidance didn't significantly predict HRQoL (.411, $p<.05)$, experiential avoidance didn't significantly predict death anxiety (.534, $p<.05)$, while experiential avoidance didn't predict the relationship between death anxiety and HRQoL $(.757, \mathrm{p}<.05)$. The researchers suggest that medical professionals in charge of diabetic patients should look beyond HRQoL and death anxiety in investigating whether there will be an occurrence of experiential avoidance.

\section{Introduction}

Diabetes Mellitus (DM) is one of the costliest medical conditions to manage due to its complications and effects on quality of life. DM occurs when there is inefficiency in insulin production or the inability of the body to utilize the insulin it produces [1]. According to WHO [2]. DM has been established to be of three types namely; type 1 , type 2 , and gestational diabetes. Type 1 diabetes formerly known as juvenile diabetes occurs when there is a deficit in insulin production thereby subjecting sufferers to regular insulin injection to help in controlling the level of glucose in the blood. On the other hand, the inability of the body to effectively utilize the already produced insulin leads to type 2 diabetes. About $90-95 \%$ of all diabetes cases are said to fall under type 2 [2]. In line with this, DM and Type 2 diabetes were interchangeably used in this study. DM risk factors include but are not limited to obesity, family history, older age, physical inactivity, lifestyle, and race [3]. While gestational diabetes according to Bellamy, et al. [4]. Is a temporary form of diabetes that only occurs during 
pregnancy, but can lead to type 2 if not well managed, and exposes both pregnant women and their infants to delivery complications.

However, one of the ultimate goals of humans is a healthy life. Health-related quality of life (HRQoL) defines an individual's overall wellness to perform and/or function daily. According to WHO [5]. HRQoL is the condition of complete physical, social and mental well-being and not only the absence of illness. It represents an individual's or group's perceived mental and physical health over some time [3]. And captures the purpose for individuals throughout life stages [6]. Several studies found that presence of DM impacts negatively on HRQoL among victims, as individuals living with DM report lower HRQoL when compared to individuals without DM [79]. DM's impact on HRQoL has been established to affect the psychological, environmental, social, and physical functioning of sufferers [10]. Which may be linked to victim's older age, lack of exercise, overweight, coronary artery disease, hypertension, retinopathy, and amputations [3,11-13].

Consequently, an individual whose HRQoL is low due to the adverse impact of DM may likely experience some psychological or emotional trauma related to death. Death Anxiety (DA) according to Carpenito-Moyet [14]. Is a condition where individuals experience fear, apprehension, or worry that relates to death or dying. DA experience is common among people who are confronted by life-threatening conditions or managing chronic illnesses with no possible cure. The concept is a trepidation spawned by awareness of death [15]. And goes beyond one's death to the death of loved ones, family, and friends [16]. Further developed DA into four dimensions explicitly; death acceptance, extremely generated death anxiety, thoughts about death, and death finality. These dimensions operate jointly to elicit death apprehension and incarcerate greater complex emotions as it depicts a huddle of death caused by discomfort, threat, unease, fear, and added negative emotional reactions [17].

In order to evade DA, patients may likely adopt a coping mechanism to help in controlling such anxiety. Experiential avoidance (EA), according to Hayes, Wilson, Gifford, Follette, and Strosahl [18]. Is a pathological behavioral pattern in which individuals aim to evade memories, emotions, thoughts, internal experiences and sensations. It is a term used in identifying emotional detachment from psychological activities that cause us pain. This form of avoidance is positive until it limits individuals from performing daily functions [19]. Although escaping from such negative sensation can be regarded as a short form of positive EA, the concept has been linked with negative psychological outcomes, such as depression, anxiety, substance use, eating disorders, and negatively affects the quality of life $[20,21]$.

\section{Diabetes-related complications}

The chronic nature of DM predisposes the body to many medical conditions, including eye disease. Retinopathy is the commonest eye disease related to diabetes, and the condition is known as the non-inflammatory disease of the retina.
According to Cheung, Mitchell, and Wong [22]. Retinopathy and maculopathy are types of diabetes-related eye disease and they are preventable. Retinopathy is significantly associated with diabetes duration, as observed in a study, a greater number of patients with diabetes recorded retinopathy to some extent after 20 years of suffering from the illness [23]. From the global stand, diabetic retinopathy contributes about $2.6 \%$ of all blindness, while an epidemiologic study reported that both the younger and older diabetic patients reported legal blindness [24]. This reciprocal relationship between the two diseases indicates why they should be studied. Across Africa, cataracts and retinopathy are common complications found in diabetic patients but they are not the major cause of mortality (death) among diabetic patients [25]. A systematic review involving 62 studies across 21 countries in the SubSaharan region pointed out that about $30.2 \%-31.6 \%$ of the sample population reported diabetic retinopathy, $0.9 \%-1.3 \%$ presented proliferative diabetic retinopathy, while $1.2 \%-4.5 \%$ reported maculopathy [25]. And these findings are related to the global research outcomes [24].

The risk of developing cardiovascular diseases rises with the increase in fasting plasma glucose levels even before diabetes diagnosis [26]. Older adults who live with diabetes have double chances of cardiovascular disease development compared to the general adult population without diabetes [27]. This medical condition is caused majorly by three preventable factors namely; diabetes, hypertension, and hyperglycemia [25]. According to a study by Global Burden of Diseases, (2014), indicated that hypertension occupies the leading position worldwide and is seconded by diabetes. The global prevalence trend of cardiovascular diseases across Northern America, Northern Ireland, Scandinavia, and Great Britain show a reduction in over 20 years of study among diabetic patients, this reduction can be linked to proper management of cardiovascular diseases and reduced smoking habits [28]. In Africa, insufficient data or improper data documentation is an issue in this area. However, in the past 2-3 decades, there has been blood pressure increase across Sub-Saharan Africa [25]. This can be linked to the WHO STEPwise surveys across Sub-Saharan Africa, which recorded high blood pressure prevalent of $19.3 \%$ in Eritrea and $39.6 \%$ in Seychelles [29]. And predicted that about 150 million people living in the Sub-Saharan region will be hypertensive by 2025 , against 80 million people predicted in 2010, and this increase may be associated with the switch from the African diet to the western diet, increased alcohol consumption, and physical inactivity.

\section{Diabetes mortality}

DM as a chronic illness is one of the leading causes of mortality across the globe. The medical condition has accounted for about 3.8 million deaths annually worldwide [30]. A prediction by GBD in 2013 projected the mortality rate by DM across (SSA) at 145,189 deaths i.e. about $1.8 \%$ of all deaths in the region [31]. Another (systematic) review in the region conducted in 2014 submitted a different result, in that DM has no contributory effect on the mortality rate caused by Non-communicable diseases (NCDs) among the African 
population compared to some diseases like cancer and CVD [32]. In 2005, a study in Mozambique predicted life expectancy of 3.5 years from diagnosis among children with type 1 diabetes under 15 years [33]. In Mali, 50\% of patients diagnosed with type 1 diabetes died within 2 years of diagnosis [34]. And in a space of 10 years, $16 \%$ mortality rate was recorded in South Africa, with a follow-up study which indicated $43 \%$ mortality rate in a space of 20 years [35]. These recorded differences may be as a result of inaccurate data-keeping and health-seeking behavior of people in this region i.e. patients with this medical condition may be managed at home and when they die, they may not be recorded in the death register.

\section{Diabetes mellitus risk factors}

DM has been liked to a higher risk of developing infection diseases including worse treatment outcomes [36]. Reduction of life expectancy by 10 years was also reported among diabetics [37]. And when diabetes co-exists with cardiovascular diseases, it can be a cause of sudden death [38].

Hepatitis B Virus (HBV) is one of the risk factors associated with DM, as the virus affects over 260 million people across the globe [2]. HBV is one of the neglected tropical diseases [39]. And studies have shown a higher prevalence of HBV among DM sufferers [40]. While patients with chronic HBV have greater chances of developing DM [41]. This reciprocal relationship may be a result of the lowered quality of life as DM complications tend to affect all parts of the body.

The use of Antiretroviral Therapy (ART) by People Living with HIV (PLWH) has aftermath effects as it increases the rates of metabolic conditions such as hyperlipidemia, body morphological changes (lipodystrophy syndrome), and impaired glucose tolerance [42]. Although studies across Europe and other western nations are yet to link HIV infection to the risk of developing T2DM [43]. The fact is evident across Asian and African populations [44]. A Taiwan study by Lo, Chen, Sheng, et al. [45]. Suggests that PLWH have six times higher chances of developing DM compared to the general population, with increased DM rates reported among PLWH in South Africa, Ethiopia [46]. And Tanzania [47].

However, across all continents, malaria has been regarded as the highest cause of mortality from infectious diseases, with an increased estimate of 213 million cases and 720,000 deaths annually [48]. In 2016 alone, 216 million cases of malaria were recorded globally and 455,000 deaths [49]. Out of these figures, Africa contributed 194.4 million cases and 407, 000 deaths [50]. The cause of malaria is linked to Plasmodium parasite (PP), with over 100 species discovered so far, among these 100 , only 5 (P. knowlesi, P. malariae, P. falciparum, P. vivax and P. ovale) have been identified to affect humans [51]. And the PP is 1-3 transmitted through a bite by female infected Anopheles mosquitoes [50]. Individuals living with T2DM are reported to be more susceptible to malaria and display a greater parasitemia when compared to the non-diabetic population [52]. Studies carried out on the parasite disease and T2DM indicate that comorbidity of the two disorders will increase the mortality rate of people living with $\mathrm{T} 2 \mathrm{DM}$ due to unending prevalence and complications in both, as over $46 \%$ prevalence increase was recorded in 2010 among DM patients in Ghana [50].

Obesity has gained much attention in the field of medicine which may be as a result of its roles in lowering life quality and expectancy. It is caused by the deposition of abdominal fat in the adipose tissue, as a result of either hereditary, chronic over-nutrition, or physical inactivity [53]. The onset increases the risk of developing T2DM, cancer, premature death, heart attacks, and/or cardiovascular diseases. Over 1.1 billion people globally are recorded to be overweight, out of which about 320 million are estimated to be obese [54]. Every year, up to 2.5 million deaths are linked to excessive Body Mass Index (BMI), with the prevalence of obesity projected at 300 million adults globally [55]. T2DM has a close relationship with lack of physical exercise and excessive body fat, as excessive BMI can trigger the development of diabetes, while diabetes complications can in turn lead to physical inactivity. A report indicates that $86 \%$ of people living with T2DM are obese or overweight; while $8.1 \%$ have morbid obesity, $52 \%$ have obesity [56]. Obesity doubles the risk of T2DM, thereby leading to premature death [57]. Having excess fat around the abdominal has been established to be a leading factor to T2DM development, as abdominal fats trigger pro-inflammatory chemicals which in turn condition the body to be less sensitive to the insulin it produces, which is known as insulin resistance. [54]. Akin to other chronic conditions such as cancer, DM is linked with intense complications, constitutes rigorous challenges to families, and incites the inability of sufferers to achieve internationally recognized developmental goals e.g., Millenium Developmental Goals (MDGs) [58]. As of 1985, about 30 million people were estimated to have been affected by this epidemic, 230 million cases were recorded in 2006, accounting for approximately $6 \%$ of the world population, and closely $80 \%$ of this number occurred in developing countries [59]. Later in 2011, IDF recorded that out of the 7 billion world population, 366 million adults aged $20-79$ years suffered DM.

This close association between DM, obesity and other chronic diseases justifies why they should be studied to ascertain how much impact they have on victims' quality of life. Therefore, the aims of this study were; to ascertain the relationship between death anxiety and health-related quality of life among diabetic patients and to evaluate the predictive roles of experiential avoidance on DA and HRQoL. The outcome will help the researchers to argue if there are other demographics that contribute to death anxiety or lower healthrelated quality of life among diabetic patients. Consequently, the following hypotheses were raised for the study

1. Death anxiety will have a significant and positive correlation with health-related quality of life among diabetic patients.

2. Experiential avoidance will significantly predict healthrelated quality of life among diabetic patients.

3. Experiential avoidance will significantly predict death anxiety among diabetic patients. 
4. Experiential avoidance will predict the relationship between health-related quality of life and death anxiety among diabetic patients.

\section{Theoretical framework}

\section{Terror management theory (greenberg, pyszcynski and solomon, 1986)}

The idea of the theory was greatly influenced by Ernest Becker's broad interdisciplinary theory of human motivation. Terror Management Theory (TMT) posits that positive illusions function in the opposite direction to illuminate death anxiety [60]. TMT is focused on how people manage not only the threats of death but understanding that such threats are ubiquitous. The theory also holds that when individuals become aware of their mortality, it can trigger existential anxiety. The existential anxiety is moderated by our collective beliefs - which Greenberg, et al. calls a cultural worldview. Culture, however, helps in different ways in reducing the terror caused by DA; as it opposes the mode of existence created by feelings of detachment, uncertainties, and dangers. The cultural space provides a structural and enabling environment for more integration, against an uncontrolled, wild and bewildering environment. Similarly, the cultural worldview provides more conservative beliefs, values, goals, and assurance of continuity of life after death, as well as helps in regulating terror caused by death anxiety. Every culture performs an anxiety-reduction function through the provision of purpose and meaning by achieving symbolic immortality. The psychological function of culture doesn't entail exposing the truth but hiding the terror caused by existential anxiety [60].

However, TMT hypothesizes that human awareness of death inevitability is been controlled in two ways: the mortality salience hypothesis and the anxiety-buffer hypothesis. According to the mortality salience hypothesis, cultural worldviews trigger a buffer from existential anxiety, and awareness of death will elevate the need by individuals to reinforce their worldview. The anxiety-buffer hypothesis holds that self-esteem is the major buffer that stands to defend individuals from existential anxiety and in turn deny mortality. Consequently, research based on the mortality salience hypothesis found exposure to death thought to draw people closer to their confederate, which implies that there is a link between existential anxiety and nationalism [61]. There is a reciprocal relationship between culture and existential anxiety as when one's nationalism is criticized, existential anxiety tends to increase and shows that any challenge to worldview may trigger the thought of mortality. On the other hand, selfesteem stands as a great buffer against existential anxiety and mortality. Self-esteem helps the individual have a sense of immortality thereby reducing existential anxiety. Self-esteem can be gained through other means such as; an individual's contribution to society or through creative work. TMT indicates that the presence of existential anxiety shows its relationship to mental health difficulties [60].

TMT is deeply rooted in the existentialist framework because of the importance it places on existentially motivated processes in human behavior. If TMT theory is to be summarized, it suggests death anxiety is a distal causal factor for a variety of socially significant motives, in particular those that center on meaning e.g. religion and politics. It provides a framework that posits the juxtaposition of instinctive self-preservation with the cognitive capacity to be aware of one's own death; this awareness creates death anxiety which can be overwhelming and paralyzing when it is insufficiently managed by cultural beliefs and a rigid sense of symbolic value. TMT warns that when the death anxiety buffers are enacted to provide some sense of immortality, they can become problematic socially. TMT also identifies the existence of death anxiety and does, in fact, show a relationship to mental health difficulties. TMT addresses general existential anxiety, which is then correlated with both anxiety and depression. In addition, TMT indicates differing levels of awareness in its terminology, salience of mortality, indicating that death anxiety is subject to different states of awareness. TMT, therefore, recognizes the three basic factors of death anxiety identified by all of the prior theories, including identification of the existence of death anxiety, its relation to mental health impairment, and identification of different levels of awareness.

\section{Methods and materials}

Data collation and analysis were performed using the quantitative method. Convenience sampling was used to recruit 105 (62; 58.5\% females) diabetic outpatients in the medical outpatients (MOP) unit at the University of Nigeria teaching hospital Ituku/Ozalla, Enugu, Nigeria. Their ages ranged from 21-75 years with a mean age of 53.45 and a standard deviation of 14.44 . Patients who gave consent to willingly participate in the study were given the questionnaires and their responses served as data for this study. The data collection lasts for a period of six (6) weeks (from mid-June 2021 to the end of July 2021). The inclusion criteria were as follows: the participant must be diagnosed with type 2 diabetes, the participant must be up to 18 years of age, the participant must have at least secondary education and be able to read and write, and must consent to participate in the study. The exclusion criteria were as follows: participant less than 18 years of age, participant diagnosed with type 1 diabetes, a participant who cannot read and understand the items of the instruments, and participant who suffered other chronic illnesses like cancer, HIV/AIDS.

The diagnosis of diabetes mellitus was based on fasting blood glucose $>7 \mathrm{mmol} / \mathrm{L}(126 \mathrm{mg} \%)$ on two occasions, or random blood glucose greater than $11.1 \mathrm{mmol} / \mathrm{dL}$ (200mg \%) [62]. The 105 participants whose data were analyzed were those who completed their questionnaires. Those with incomplete questionnaires were excluded in order not to introduce any error in data analysis. Their exclusion did not induce significant bias in the study because additional participants were recruited to replace them.

\section{Instruments}

The following instruments; the Death Anxiety InventoryRevised (DAI-R), Acceptance and Action Questionnaire (AAQ), and Diabetes Quality of Life Questionnaire (DQOLO) were used in this study to measure the variables. The DAI-R developed by Thomas-Sabado, Gomez-Benito [16]. And Limonero. Is 
a 17-item self-administered four-dimensional scale that assesses anxiety generated by death. The dimensions include; Death Acceptance with items 1,8,12,\&16, Death Finality having items 11, 14, \& 17, thoughts about Death with items 4,9,10, \& 13, and Externally Generated Death Anxiety containing items $2,3,5,6,7, \& 15$. The 17-item scale has a 5-point Likert format of Totally Agree $=5$, Strongly agree $=4$, Agree $=3$, Disagree $=2$, and Strongly Disagree= 1, with internal consistency Cronbach alpha of .92. Hayes, et al. (2000), developed Acceptance and Action Questionnaire (AAQ) to assess experiential avoidance and psychological acceptance. The 9-item scale has a 7-point Likert format having $1=$ Never true, $2=$ Very seldom true, $3=$ Seldom true, 4= Sometimes true, 5=Frequently almost true, $6=$ Always true, $7=$ Always true, with the internal consistency of .70 , and test re-test reliability of .71 , and the Diabetes Quality of Life Questionnaire (DQOLQ) which is a 5-point Likert scale developed to assess diabetes-related QoL. The scale has two general formats i.e $1=$ Never, $2=$ Very Seldom, Sometimes, $4=$ Often, $5=$ All the time and $1=$ Very Satisfied, $2=$ Moderately Satisfied, 3= Neither, $4=$ Moderately Dissatisfied, $5=$ Very Dissatisfied. Test takers whose scores high indicate dissatisfaction or negative perception of DQoL. While the scale has proven a convergent validity and internal consistency of $r=$ 0.78-0.92 among the subscales.

\section{Procedure}

Through the help of research assistants (who were registered nurses at the MOP unit), the researchers approached the participants before their consultations, introduced themselves and the essence of the research. Participants who willingly consented to participate were issued the questionnaires and only those who filled their own correctly were scored and served as data for this study. At the end of the data collation, the researchers debriefed and thanked them for participating in the study.

\section{Design/statistics}

This is a cross-sectional study and both correlation and hierarchical linear regression analysis was adopted, while the Statistical Package for Social Science (SPSS) version 20 was the statistical tool used. The Statistical values with probabilities less than $0.05(\mathrm{p}<0.5)$ were considered significant.

\section{Results}

There were 105 participants with a mean age of 53.45 years and a standard deviation of 14.44 (Table 1).

Table 2 above shows that there is no significant correlation between death anxiety and HRQoL, hence the first hypothesis tested which stated that "death anxiety will significantly correlate HRQoL" is not confirmed, hence rejected. It is because $\mathrm{r}=-.036$ is not up to 1 and also sig value of .712 is higher than the threshold $\mathrm{f}$ at $\mathrm{p}<.05$. The table also indicates that both variables have negative interactions, which implies that when one variable is going up the other will be going down.

\section{Coefficients}

Table 3 shows that experiential avoidance did not predict HRQoL because of the sign. The value of .411 is higher than
Table 1: Age: Descriptive statistics

\begin{tabular}{|c|c|c|c|c|c|}
\hline & N & Minimum & Maximum & Mean & Std. Deviation \\
\hline AGE & 105 & .00 & 75.00 & 53.4470 & 14.44106 \\
\hline
\end{tabular}

Table 2: Shows correlation between death anxiety and HRQoL.

\begin{tabular}{|c|c|c|}
\hline & HRQoL & Death \\
\hline HRQoL Pearson Correlation & 1 & -0.036 \\
\hline Sig. (2-tailed) & & 0.712 \\
\hline Sum of squares and cross-products & 6837 & -618.7 \\
\hline Covariance & 65.741 & -5.949 \\
\hline N & 105 & 105 \\
\hline Death Pearson Correlation & -0.036 & 1 \\
\hline Sig. (2-tailed) & -712 & \\
\hline Sum of squares and cross-products & -618.7 & 42043 \\
\hline Covariance & -5.949 & 404.26 \\
\hline N & 105 & 105 \\
\hline
\end{tabular}

Table 3: Summary table.

\begin{tabular}{|c|c|c|c|c|c|c|}
\hline \multicolumn{2}{|c|}{$\begin{array}{l}\text { Unstandardized } \\
\text { Coefficients }\end{array}$} & \multicolumn{2}{|c|}{$\begin{array}{l}\text { Standardized } \\
\text { Coefficients }\end{array}$} & \multicolumn{3}{|c|}{ 95.0\% Confidence Interval for } \\
\hline Model & B & $\begin{array}{l}\text { std. } \\
\text { Error }\end{array}$ & Beta & T Sig. & $\begin{array}{l}\text { Lower } \\
\text { Bound }\end{array}$ & $\begin{array}{l}\text { Upper } \\
\text { Bound }\end{array}$ \\
\hline $\begin{array}{c}1 \text { (constant) } \\
41.677\end{array}$ & 35.915 & 2.905 & & 12.364 & 000 & 30.154 \\
\hline HRQoL .166 & 0.049 & 0.059 & & .826 & .411 & -0.68 \\
\hline Death .062 & 0.015 & 0.024 & 0.081 & .623 & .523 & -.032 \\
\hline $\begin{array}{c}2 \text { (constant) } \\
54.338\end{array}$ & 38.26 & 8.105 & 0.061 & 4.720 & .000 & 22.181 \\
\hline HRQoL .353 & -0.004 & 0.18 & -.006 & -.022 & .983 & -.361 \\
\hline Death .264 & -0.031 & -149 & -0.127 & -.206 & .837 & -.326 \\
\hline Regression .008 & 0.001 & 0.003 & 0.207 & .310 & .757 & -.006 \\
\hline
\end{tabular}

the threshold value of at $\mathrm{p}<.05$. Also, experiential avoidance didn't significantly predict death anxiety because of the sign. Value of .534 is higher than the threshold of at $\mathrm{p}<.05$. Finally, experiential avoidance didn't predict the relationship between death anxiety and HRQoL because the sign value of .757 is higher than the threshold value of at $\mathrm{p}<.05$ hence the hypotheses $2,3, \& 4$ tested were not supported.

\section{Discussion}

The study investigated the predictive roles of experiential avoidance in the relationship between death anxiety and health-related quality of life among diabetic patients in Nigeria. Results of the study showed that there was a negative relationship between death anxiety and HRQoL. This indicates that diabetic patients with high death anxiety experienced a decreased health-related quality of life. Therefore, the first hypothesis tested which states that death anxiety will have a significant and positive correlation on health-related quality of life among diabetic patients was not supported. In other words, the existence of death anxiety among individuals suffering from chronic illness such as diabetes, there will be lowered HRQoL. The results of this study are consistent with previous studies that reported a negative relationship between death 
anxiety and QoL, where the presence of death anxiety predicted lower QoL among individuals with chronic illnesses [63,64]. Also, anxiety together with other psychological constructs like depression have been linked to poor and/or lower QoL among patients with heart failure [65-68]. Death anxiety was present among a greater number of hemodialysis patients while they recorded low to moderate QoL, and among the domains of QoL, psychological and physical domains had the worst reductions [69]. Furthermore, anxiety was found to be negatively associated with the psychological, environmental, and social relationships domains of QoL [70]. In line with this assertion, Brown, and Roose [71]. Suggested that age influences the anxiety and depressive symptomatology on the physical domain of QoL.

The result showed that HRQoL did not predict experiential avoidance. This shows that having high HRQoL will not subject diabetic patients to avoid emotional pain or discomfort. Thus, the second hypothesis which stated that health-related quality of life will significantly predicts experiential avoidance among diabetic patients was not supported. This study outcome lends empirical support to previous studies [72,73]. Which showed that negative relation of anxiety and depression didn't predict emotional avoidance, and negative relationship between experiential avoidance and value, which is closely related to the social tenet of quality of life. This further suggests that among diabetic patients, the tenets of HROoL cannot predict any form of experiential avoidance. Also, the result also that death anxiety did not significantly predict experiential avoidance. This indicates that death-related anxiety among diabetic patients cannot subject them to undergo experiential avoidance. Thus, the third hypothesis which stated that death anxiety will significantly predicts experiential avoidance among diabetic patients was not supported. This finding is consistent with other empirical findings [74,75]. Which showed that higher experiential avoidance experienced through selfdisclosure conversation sequentially increases social anxiety, while experiential avoidance didn't significantly contribute over and above the contributions of anxiety sensitivity. This further suggests that among diabetic patients, having higher death anxiety cannot subject diabetic patients to experiential avoidance. Lastly, experiential avoidance didn't predict the relationship between death anxiety and HRQoL. This suggests that among diabetic patients, experiential avoidance cannot influence the correlation between death anxiety and HRQoL [76].

\section{Implications}

The study findings suggest clinical implications in regards to the psychological wellbeing and health-related quality of life among diabetic patients. One of the findings suggests that diabetic patients with high death anxiety experienced a decreased health-related quality of life. This indicates that the existence of death anxiety among individuals suffering from chronic illness such as diabetes, there will be lowered HRQoL. Also, experiential avoidance did not significantly predict death anxiety. This indicates that experiential avoidance cannot determine whether death anxiety will increase or reduce among diabetic patients. Experiential avoidance did not predict HRQoL. This suggests that experiential avoidance cannot determine whether HRQoL will increase or reduce among diabetic patients. Finally, experiential avoidance did not predict the relationship between death anxiety and HRQoL. This suggests that among diabetic patients, the relationship between death anxiety and HRQoL cannot be influenced by the existence of experiential avoidance.

\section{Future study}

From the outcome of our study, we project that the findings of this study would add to plans and strategies used in the management of psychological challenges associated with chronic illnesses and improvement of HRQoL among diabetic patients. Also, we recommend that future researchers should explore other variables to understand different factors that affect diabetic patients. Lastly, since we found that the existence of death anxiety among diabetic patients lowers the health-related quality of life, we advocate that counseling services should be part of diabetes and/or other chronic illnesses' treatment plans.

\section{Limitations}

Studies of this nature are without limiting factors. The number of participants (105) used in this study limits the generalizability of its findings. The study was carried out in a teaching hospital in southeast, Nigeria, thus, limiting the generalization of the study results to the entire Nigerian population. Also, some participants might not have answered some questions honestly, which may lead to erroneous study outcomes.

\section{Conclusion}

From the results, we conclude that death anxiety has a negative relationship with HRQoL among diabetic patients, in that existence of death anxiety among individuals suffering from chronic illness such as diabetes, there will be lowered HRQoL. In addition, the relationship between HRQoL and death anxiety was not influenced by experiential avoidance. Trained psychologists should be part of the medical team when it comes to the management of chronic illnesses such as diabetes. This will go a long way in helping the patients manage some psychological factors (e.g., death anxiety) associated with diabetes, while medical professionals in charge of diabetic patients should look beyond HRQoL and death anxiety in investigating whether such patients will experience experiential avoidance.

\section{Ethical consideration}

The researchers obtained approval of the ethical board at the University of Nigeria teaching hospital Ituku/Ozalla (UNTH), Enugu, Nigeria, with the ref No: NHREC/05/01/2008BFWA00002458-1RB00002323.

\section{Authors' contribution}

All the authors contributed equally to this study, they read and approved the final manuscript. 


\section{References}

1. WHO (1999) Definition, Diagnosis and Classification of Diabetes Mellitus and its Complications. Part 1: Diagnosis and Classification of Diabetes Mellitus (WHO/NCD/NCS/99.2). Geneva. Link: https://bit.ly/3G4xO7d

2. WHO (2010) Global report on diabetes. Link: https://bit.ly/3IGFQVz

3. CDC (2000) Measuring Healthy Days: Popula- tion Assessment of HealthRelated Quality of Life. Atlanta GA: 44

4. Bellamy L, Casas JP, Hingorani AD, Williams D (2009) Type 2 diabetes mellitus after gestational diabetes: a systematic review and meta-analysis. Lancet 373: 1773-1779. Link: https://bit.ly/3IXC3U7

5. WHOQOL Measuring Quality of Life (1997) Division of Mental Health and Prevention of Substance Abuse. World Health Organization. WHO/MSA/MNH/ PSF/974. Link: https://bit.ly/3rUdAYJ

6. Bakas T, McLennon SM, Carpenter JS, Buelow JM, Otte JL, et al. (2012) Systematic review of health related quality of life models. Health Qual Life Outcomes 10: 134. Link: https://bit.ly/33YdVI7

7. Morales M, Navas A, Filomena M, Jimenez R, Maria J, et al. (2015) Health related quality of life in patients with type 2 diabetes mellitus in a rural area. $J$ Diabetes Metab 6: 1-5. Link: https://bit.ly/35mlimJ

8. Eljedi A, Mikolajczyk RT, Kraemer A, Laaser U (2006) Health-related quality of life in diabetic patients and controls without diabetes in refugee camps in the Gaza strip: a cross-sectional study. BMC Public Health 6: 268. Link: https://bit.ly/3o4X86K

9. Thommasen HV, Zhang W (2006) Health-related quality of life and type 2 diabetes: a study of people living in the Bella Coola Valley. Br Columbia Med $\mathrm{J}$ 48: 272. Link: https://bit.ly/3ADvbbb

10. Kakhki AD (2013) Health-related quality of life of diabetic patients in Tehran Int J Endocrinol Metabol 11: e7945. Link: https://bit.ly/3H8kL5R

11. First Nations and Inuit Regional Health Survey National Steering Committee (2009) First Nations and Inuit Regional Health Survey National Report. Link: https://bit.ly/3fZcQvJ

12. Jacobson AM, Samson JA, de Groot M (1994) The evaluation of two measures of quality of life in patients with type I and type II diabetes. Diabetes Care 17 267- 274. Link: https://bit.ly/3Gid3oR

13. Trief PM, Wade MJ, Pine D, Weinstock RS (2003) A comparison of healthrelated quality of life of elderly and younger insulin-treated adults with diabetes. Age Ageing 32: 613- 618. Link: https://bit.ly/3rSVwhx

14. Carpenito-Moyet LJ (2008) Handbook of nursing diagnosis. Philadelphia, PA Lippincott, Williams \& Wilkins. Link: https://bit.ly/34bjTPA

15. Abdel-Khalek AM (2005) Death anxiety in clinical and non-clinical groups. Death Stud 29: 251-259. Link: https://bit.ly/34bjUmC

16. Tomas-Sabado J, Gomez-Benito J (2005) Concurrent and divergent validity of the Spanish form of Templer's Death Anxiety Scale. Psychol Rep 91: 11161120.

17. Neimeyer RA, Moser R, Wittkowski J (2003) Assessing attitudes towards dying and death: Psychometric considerations. Omega 47: 45-76. Link: https://bit.ly/32zRHVY

18. Hayes SC, Wilson KG, Gifford EV, Follette VM, Strosahl K (1996) Experiential avoidance and behavioral disorders: A functional dimensional approach to diagnosis and treatment. Journal of Consulting and Clinical Psychology 64: 1152-1168. Link: https://bit.ly/349ibht

19. Lopez JC, Ruiz FJ, Feder J, Barbero AR, Suarez JJ, et al. (2010) The Role of Experiential Avoidance in the Performance on a High Cognitive Demand Task. International Journal of Psychology and Psychological Therapy 10: 475-488. Link: https://bit.ly/3g1GWPo
20. Kashdan TB, Morina N, Priebe S (2009) Post-traumatic stress disorder, socia anxiety disorder, and depression in survivors of the Kosovo War: Experiential avoidance as a contributor to distress and quality of life. J Anxiety Disord 23: 185-196. Link: https://bit.ly/346mnP3

21. Bohr-Feld C (2017) The role of experiential avoidance for the quality of life in a sample of patients with diverse personality disorders. University of Twente. Link: https://bit.ly/3H9JHu2

22. Cheung N, Mitchell P, Wong TY (2010) Diabetic retinopathy. Lancet 376: 124 136. Link: https://bit.ly/3nYO8jC

23. Arévalo JF (2013) Retinal and Choroidal Manifestations of Selected Systemic Diseases. Springer Science+Business Media. New York. Link: https://bit.ly/3u8IKzp

24. Bourne RR, Stevens GA, White RA, Smith JL, Flaxman SR, et al, (2013) For the Vision Loss Expert Group. Causes of vision loss worldwide, 1990-2010: a systematic analysis. Lancet Glob Health 1: e339-349. Link: https://bit.ly/3r4hVtf

25. Atun R, Davies JI, Gale EAM, Bärnighausen T, Beran D, et al. (2017) Diabetes in sub-Saharan Africa: from clinical care to health policy. Lancet Diabetes Endocrinol 5: 622-627. Link: https://bit.ly/3ABE70j

26. Singh GM, Danaei G, Farzadfar F, Stevens GA, Woodward M, et al. (2013) The age-specific quantitative effects of metabolic risk factors on cardiovascular diseases and diabetes: a pooled analysis. PLoS One 8: e65174. Link: https://bit.ly/3H7TfFR

27. Sarwar N, Gao P, Seshasai SR, Gobin R, Kaptoge S, et al. (2010) Diabetes mellitus, fasting blood glucose concentration, and risk of vascular disease: a collaborative meta-analysis of 102 prospective studies. Lancet 375: 2215 2222. Link: https://bit.ly/3rOkAUF

28. Barengo NC, Katoh S, Moltchanov V, Tajima N, Tuomilehto J (2008) The diabetes-cardiovascular risk paradox: results from a Finnish population-based prospective study. Eur Heart J 29: 1889-1895. Link: https://bit.ly/3G7aDZX

29. Addo J, Smeeth L, Leon DA (2007) Hypertension in sub-Saharan Africa: a systematic review. Hypertension 50: 1012-1018. Link: https://bit.ly/35mlOkF

30. World Health Organization (2007) The Burden of chronic diseases in the African Region preventing chronic diseases a vital investment. World Diabetes Foundation Summit, World Health Organization Africa.

31. GBD Causes of Death Collaborators (2017) Global, regional, and nationa age-sex specific mortality for 264 causes of death, 1980-2016: a systematic analysis for the Global Burden of Disease Study 2016. Lancet 390: 11511210. Link: https://bit.ly/3H5ouRD

32. Sankoh O, Byass P (2014) Cause-specific mortality at INDEPTH Health and Demographic Surveillance System Sites in Africa and Asia: concluding synthesis. Glob Health Action 7: 25590. Link: https://bit.ly/3G30gEQ

33. Beran D, Yudkin JS, de Courten M (2005) Access to care for patients with insulinrequiring diabetes in developing countries: case studies of Mozambique and Zambia. Diabetes Care 28: 2136-2140. Link: https://bit.ly/3KR3wZo

34. Sathl-Aidmtac I (1999) Le diabète juvénile au Mali. Rev Fr Endocrinol Clin 40: 513-521.

35. Gill GV, Huddle KRL, Monkoe G (2005) Long-term (20 years) outcome and mortality of type 1 diabetic patients in Soweto, South Africa. Diabet Med 22 1642-1646. Link: https://bit.ly/3rSO99W

36. Benfield T, Jensen JS, Nordestgaard BG (2007) Influence of diabetes and hyperglycaemia on infectious disease hospitalization and outcome. Diabetologia 50: 549-554. Link: https://bit.ly/3АB0X8U

37. Panzram G (1987) Mortality and survival in type 2 (non-insulin-dependent) diabetes mellitus. Diabetologia 30: 123-131. Link: https://bit.ly/3ubYuQW 
38. Zimmet P, Alberti KGMM, Shaw J (2001) Global and societal implications of the diabetes epidemic. Nature 414: 782-787. Link: https://bit.ly/3G6PWgO

39. 0 Hara GA, McNaughton AL, Maponga T, Jooste P, Ocama P, et al. (2017) Hepatitis B virus infec- tion as a neglected tropical disease. PLoS Negl Trop Dis 11: e0005842. Link: https://bit.ly/3r4Goi1

40. Zhu H, Wang Y, Yu L, Xu Y, Zhou H, et al. (2016) Serological and molecular analysis on the relationships between type 2 diabetes mellitus and hepatitis $B$ virus infection. J Infect Dev Ctries 10: 837-844. Link: https://bit.ly/3G5s3WL

41. Hong YS, Chang Y, Ryu S, Cainzos-Achirica M, Kwon MJ, et al. (2017) Hepatitis $B$ and $C$ virus infection and diabetes mellitus: A cohort study. Sci Rep 7: 4606. Link: https://bit.ly/34bV5qu

42. Brar I, Shuter J, Thomas A, Daniels E, Absalon J (2007) A comparison of factors associated with prevalent diabetes mellitus among HIV-Infected antiretroviral- naive individuals versus individuals in the National Health and Nutritional Examination Survey cohort. J Acquir Immune Defic Syndr 45: 6671. Link: https://bit.ly/3KL5Y3j

43. Ali MK, Magee MJ, Dave JA, Ofotokun I, Tungsiripat M, et al. (2014) HIV and Metabolic, Body, and Bone Disorders: What We Know From Low- and Middle-Income Countries. J Acquir Immune Defic Syndr 67: S27-S39. Link: https://bit.ly/3r4cCd9

44. Dunachie S, Chamnan P (2019) The double burden of diabetes and global infection in low and middle- income countries. Trans R Soc Trop Med Hyg 113: 56 -64. Link: https://bit.ly/3G4few6

45. Lo YC, Chen MY, Sheng WH, Hsieh SM, Sun HY, et al. (2009) Risk factors for incident diabetes mel- litus among HIV-infected patients receiving combination antiretroviral therapy in Taiwan: a case-control study. HIV Med 10: 302-309. Link: https://bit.ly/3KKV6CH

46. Abrahams Z, Dave JA, Maartens G, Levitt NS (2015) Changes in blood pressure, glucose levels, insulin secretion and anthropometry after long term exposure to antiretroviral therapy in South African women. AIDS Res Ther 12 24. Link: https://bit.ly/3rTfd98

47. Maganga E, Smart LR, Kalluvya S, Kataraihya JB, Saleh AM, et al. (2015) Glucose Metabolism Disorders, HIV and Antiretroviral Therapy among Tanzanian Adults. PLoS One 10: e0134410. Link: https://bit.ly/3HaeMO4

48. Institute for Health Metrics and Evaluation. Global burden of disease (GBD) (2017). Link: https://bit.ly/3fYKNNh

49. World Health Organisation (2017). World Malaria Report. WHO, Geneva, Switzerland. Link: https://bit.ly/3g2PK7G

50. Acquah S (2019) Linking malaria to type 2 diabetes mellitus: A review. J Ghana Sci Association 18 1. Link: https://bit.ly/32zzojF

51. White $N$ (2008) Plasmodium knowlesi: the fifth human malaria parasite. Link: https://bit.ly/3H7Uwg7

52. Danquah I, Bedu-Addo G, Mockenhaupt FP (2010) Type 2 diabetes mellitus and increased risk for malaria infection. Emerg Infect Dis 16: 1601-1604. Link: https://bit.ly/3fYLImj

53. Chalupova L, Halupova L, Zakovska A, Krejci G, Svestak M, et al. (2016) CTRP1: A Molecular Link between Obesity and Hypertension. J Mol Biomark Diagn 7 289. Link: https://bit.ly/3H88uym

54. Parmar MY (2008) Obesity and Type 2 diabetes mellitus. Integr Obesity Diabetes 4: 1-2.

55. Kopelman PG (2000) Obesity as a medical problem. Nature 404: 635-643. Link: https://go.nature.com/3ooVP31

56. Daousi C, Casson IF, Gill GV, MacFarlane IA, Wilding JP, et al. (2006) Prevalence of obesity in type 2 diabetes in secondary care: association with cardiovascular risk factors. Postgrad Med J 82: 280-284. Link: https://bit.ly/3r3FCSe

57. Aucott LS (2008) Influences of weight loss on long-term diabetes outcomes Proc Nutr Soc 67: 54-59. Link: https://bit.ly/3u4gU6d

58. Oguejiofor O, Odenigbo C, Onwukwe C (2014) Diabetes in Nigeria: Impact, Challenges, Future Directions. Endocrinol Metab Synd 3: 130. Link: https://bit.ly/33ZPDam

59. Roglic G, Unwin N, Bennett PH, Mathers C, Tuomilehto J (2005) The burden of mortality attributable to diabetes: realistic estimates for the year 2000 . Diabetes Care 28: 2130-2135. Link: https://bit.ly/3u8nPeH

60. Greenberg J, Koole S, Pyszczynski T (2004) Handbook of Experimental Existential Psychology Guilford Press. Link: https://bit.ly/3ACBmfR

61. Hoelterhoff M (2015) A theoretical exploration of death anxiety. J Applied Psychology Social Sci 1: 1-17. Link: https://bit.ly/3o5KJzx

62. WHO/IDF (2006) Definitions and Diagnosis of Diabetes and Intermediate Hyperglycemia. World Health Organization. Link: https://bit.ly/3o51hHQ

63. Aburuz ME (2018) Anxiety and depression predicted quality of life among patients with heart failure. J Multidiscip Healthc 11: 367-373. Link: https://bit.ly/32G5avC

64. Soleimani MA, Lehto RH, Negarandeh R, Bahrami N, Nia HS (2016) Death Anxiety and Quality of Life in Iranian patients with cancer. Asia Pac J Onco Nurs 3: 183-191. Link: https://bit.ly/3043S4P

65. Serafini G, Pompili M, Innomorati M, lacorossi G, Cuomo I, et al. (2010) The impact of anxiety, depression, and suicidality on quality of life and functional status of patients with congestive heart failure and hypertension: an observational cross-sectional study. Prim Care Companion J Clin Psychiatry 12: PCC.09m00916. Link: https://bit.ly/3u4HkoG

66. Uchmanowicz I, Gobbens RJ (2015) The relationship between frailty, anxiety and depression, and health-related quality of life in elderly patients with heart failure. Clin Interv Aging. 10: 1595-1600. Link: https://bit.ly/3ADqP4c

67. Aggelopoulou Z, Fotos NV, Chatziefstratiou AA, Giakoumidakis K, Elefsiniotis I, et al. (2017) The level of anxiety, depression and quality of life among patients with heart failure in Greece. Appl Nurs Res 34: 52-56. Link: https://bit.ly/3H83gTs

68. Tsuchihashi-Makaya M, Kato N, Chishaki A, Takeshita A, Tsutsui H (2009) Anxiety and poor social support are independently associated with adverse outcomes in patients with mild heath failure. Circ J 73: 280-287. Link: https://bit.ly/34hupow

69. Ghiasi Z, Alidadi A, Payandeh A, Emami A, Lotfinia S (2021) Health-related quality of life and death anxiety among hemodialysis patients. Zahedan J Res Med Sci 23: e98400. Link: https://bit.ly/3FZVr0x

70. Byrne GJ, Sarma SI (2013) Relationship between anxiety and quality of life in older mental health patients. Australian J Ageing. 33: 201-204.

71. Brown PJ, Roose SP (2011) Age and anxiety and depressive symptoms: The effect on domains of quality of life. Int J Geriatr Psychiatry 1260-1266. Link: https://bit.ly/3ILvSCp

72. Imani E, Shahabizadah F, Mahmoodirad A (2017). The role of anxiety and depression on acceptance and action, considering emotional schemas in diabetics of Birjand (Iran). Electronic Physician 9: 5551-5559. Link: https://bit.ly/3u0u4Bj

73. Boullion GQ (2015) The Relationships among Anxiety, Experiential Avoidance and Valuing in Daily Experiences.Link: https://bit.ly/3KNMCe0

74. Kashdan TB, Goodman FR, Machell KA, Kleiman EM, Monfort SS., et al. (2014) A Contextual Approach to Experiential Avoidance and Social Anxiety: Evidence

Citation: Ezaka ES, Nassif RN, Chibuike OP, Okeke S, Chukwubuzo OT, et al. (2022) Relationship between death anxiety and health-related quality of life among diabetic patients: The predictive roles of experiential avoidance. Glob J Obes Diabetes Metab Syndr 9(1): 011-019. DOI: https://dx.doi.org/10.17352/2455-8583.000056 
from an Experimental Interaction and Daily Interactions of People with Social Anxiety Disorder. HHS Public Assess 14: 769-781. Link: https://bit.ly/3Ile8YA

75. Wheaton MG, Noah CM, Berman NC, Jonathan SM, Abramowitz J (2010) The Contribution of Experiential Avoidance and Anxiety Sensitivity in the Prediction of Health Anxiety. J cognitive psychotherapy 24. Link: https://bit.ly/32Ge7ol
76. Global Burden of Metabolic Risk Factors for Chronic Diseases Collaboration (2014) Cardiovascular disease, chronic kidney disease, and diabetes mortality burden of cardiometabolic risk factors from 1980 to 2010: a comparative risk assessment. Lancet Diabetes Endocrinol 2: 634-647. Link: https://bit.ly/3H6cj7b

Discover a bigger Impact and Visibility of your article publication with

\section{Peertechz Publications}

\section{Highlights}

* Signatory publisher of ORCID

* Signatory Publisher of DORA (San Francisco Declaration on Research Assessment)

* Articles archived in worlds' renowned service providers such as Portico, CNKI, AGRIS, TDNet, Base (Bielefeld University Library), CrossRef, Scilit, J-Gate etc.

* Journals indexed in ICMJE, SHERPA/ROMEO, Google Scholar etc.

* OAI-PMH (Open Archives Initiative Protocol for Metadata Harvesting)

* Dedicated Editorial Board for every journa

* Accurate and rapid peer-review process

* Increased citations of published articles through promotions

- Reduced timeline for article publication

Submit your articles and experience a new surge in publication services (https://www.peertechz.com/submission).

Peertechz journals wishes everlasting success in your every endeavours.

Citation: Ezaka ES, Nassif RN, Chibuike OP, Okeke S, Chukwubuzo OT, et al. (2022) Relationship between death anxiety and health-related quality of life among diabetic patients: The predictive roles of experiential avoidance. Glob J Obes Diabetes Metab Syndr 9(1): 011-019. DOI: https://dx.doi.org/10.17352/2455-8583.000056 